\title{
Characteristics of compounds that cross the blood-brain barrier William A Banks
}

\author{
Address: Veterans Affairs Medical Center-St Louis, 915 N. Grand Blvd, St. Louis, MO 63106, USA \\ Email: William A Banks - bankswa@slu.edu
}

from Drug Discovery for Neurodegeneration Conference

Washington, DC, USA. 2-3 February 2009

Published: 12 June 2009

BMC Neurology 2009, 9(Suppl I):S3 doi: 10.1 I86/147|-2377-9-SI-S3

This article is available from: http://www.biomedcentral.com/I47I-2377/9/SI/S3

(c) 2009 Banks; licensee BioMed Central Ltd.

This is an open access article distributed under the terms of the Creative Commons Attribution License (http://creativecommons.org/licenses/by/2.0), which permits unrestricted use, distribution, and reproduction in any medium, provided the original work is properly cited.

\begin{abstract}
Substances cross the blood-brain barrier (BBB) by a variety of mechanisms. These include transmembrane diffusion, saturable transporters, adsorptive endocytosis, and the extracellular pathways. Here, we focus on the chief characteristics of two mechanisms especially important in drug delivery: transmembrane diffusion and transporters. Transmembrane diffusion is nonsaturable and depends, on first analysis, on the physicochemical characteristics of the substance. However, brain-to-blood efflux systems, enzymatic activity, plasma protein binding, and cerebral blood flow can greatly alter the amount of the substance crossing the BBB. Transport systems increase uptake of ligands by roughly 10 -fold and are modified by physiological events and disease states. Most drugs in clinical use to date are small, lipid soluble molecules that cross the BBB by transmembrane diffusion. However, many drug delivery strategies in development target peptides, regulatory proteins, oligonucleotides, glycoproteins, and enzymes for which transporters have been described in recent years. We discuss two examples of drug delivery for newly discovered transporters: that for phosphorothioate oligonucleotides and for enzymes.
\end{abstract}

\section{Introduction}

The blood-brain barrier (BBB) represents a major obstacle to the delivery of drugs to the central nervous system (CNS). The BBB consists of several barriers in parallel, with the two that are best described being the vascular $\mathrm{BBB}$, consisting primarily of the capillary bed, and the blood-cerebrospinal fluid (blood-CSF) barrier, consisting primarily of the choroid plexus [1]. Although drug delivery tends to focus on the vascular BBB, the blood-CSF barrier also presents special opportunities [2]. At both sites, the $\mathrm{BBB}$ is formed by a monolayer of cells that are cemented together by tight junctions and have other mechanisms that control or retard leakage of plasma into the CNS (Figure 1). Barrier function at the BBB often depends on more than physical considerations and can be bolstered by enzymatic and brain-to-blood transporter functions [3].

The BBB serves roles other than that of blocking circulating substances from entering the CNS. It also facilitates and regulates the entry of many substances that are critical to CNS function and secretes substances into the blood and CNS. These extra-barrier functions allow the BBB to influence the homeostatic, nutritive, and immune environments of the CNS and to regulate the exchange of informational molecules between the CNS and blood [4]. An understanding of the barrier and extra-barrier aspects 


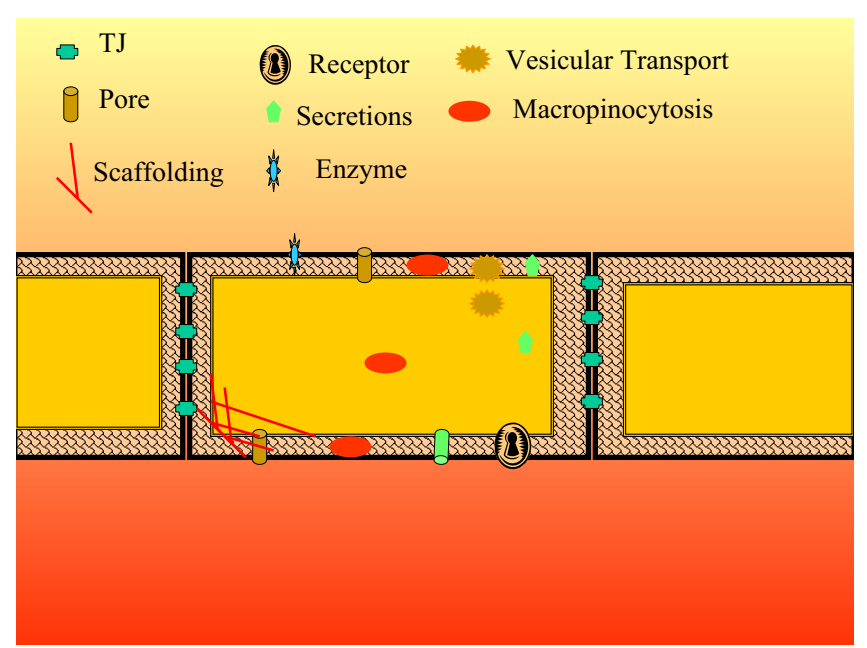

Figure I

A generic brain barrier. Adult mammalian brain barriers reduce uncontrolled leakage by constituting a monolayer of cells characterized by intercellular tight junctions, decreased macropinocytosis, and decreased fenetrae. Variations on this theme are seen at the vascular brain barrier, blood-CSF barrier, and the specialty CNS barriers such as the blood-retinal barrier. Most brain barriers have a combination of the other features shown. Pores are saturable transporters that can be energy dependent (as exemplified by P-glycoprotein) or energy independent (GLUT-I), located at the luminal or abluminal membrane, and transport bidirectionally or unidirectionally into or out of the cytoplasm. Saturable transport can also be vesicular based and brain barriers likely have many types of vesicular systems (for example, receptormediated transcytosis, clathrin-dependent transport, podocytosis, and caveolae). Scaffolding (for example, actin) is likely highly dynamic and involved in tight junction function and vesicular trafficking. Barrier cells contain receptors (binding sites coupled to intracellular machinery) as well as transporters (binding sites coupled to machinery involved in translocation of the ligand). Brain barriers are enzymatically active and this activity can act as another layer of barrier, and they can secrete substances such as cytokines, nitric oxide, and prostaglandins from either their CNS or peripheral side.

of BBB physiology is critical to developing drugs that can access the CNS [5].

\section{General characteristics of the blood-brain barrier}

Three major modifications to the capillary bed of the brain prevent the formation of a plasma ultrafiltrate in the CNS (Figure 1): tight junctions that cement together brain endothelial cells that are in apposition, a greatly reduced rate of pinocytosis, and a lack of intracellular fenestrations [6]. These modifications prevent the unregulated leakage of serum proteins into the CNS under normal conditions. Substances are still able to cross the vascular BBB by a vari- ety of mechanisms. These mechanisms include transmembrane diffusion, saturable transport, adsorptive endocytosis, and the extracellular pathways. Below, we discuss transmembrane diffusion and saturable transporters. Reviews on adsorptive endocytosis and the extracellular pathways can be found elsewhere $[7,8]$.

\section{Transmembrane diffusion}

Most drugs cross the BBB by transmembrane diffusion [9]. This is a non-saturable mechanism that depends on the drug melding into the cell membrane. A low molecular weight and high degree of lipid solubility favor crossing by this mechanism. However, a drug taken up by the membranes that form the BBB must then partition into the aqueous environment of the brain's interstitial fluid to exert an effect. As a result, a substance that is too lipid soluble can be sequestered by the capillary bed and not reach the cells behind the BBB. Lipid solubility also favors uptake by the peripheral tissues; this, in turn, lowers the concentration of the drug in blood. Thus, while lipid solubility can increase transport rate across the $\mathrm{BBB}$, it can also lower the amount of the drug presented to the BBB. The percent of administered drug entering the brain is determined by both the rate of transport across the $\mathrm{BBB}$ and the amount of drug presented to the brain [5]. Use of lipid solubility to improve drug delivery to the brain must thus find the balance between increased permeation of the BBB and decreased concentrations in blood.

Factors in addition to lipid solubility affect the ability of a drug to partition from blood into the BBB. These include charge, tertiary structure and degree of protein binding. Chief among these secondary factors, however, is molecular weight. The best approximation of the influence of size on $\mathrm{BBB}$ penetration is that it is inversely related to the square route of molecular weight. Reviews often quote an absolute cut-off of 400 to $600 \mathrm{Da}$ for penetration of the $\mathrm{BBB}$, but these arise from a misreading of the literature. The 'Rule of 5 ' of Lipinski found that from a library of drugs selected for gastrointestinal absorption, few substances were over $500 \mathrm{Da}[10]$. Some reviewers have uncritically applied the Rule of 5, including this one, to the BBB. A study of 27 substances by Levin [11] found that the four drugs in this groups with molecular weights over 400 Da had no measurable brain uptake. However, it is now known that these substances are all substrates for Pglycoprotein, a major brain-to-blood, or efflux, pump located at the $\mathrm{BBB}$ that prevents or greatly retards a large number of small, lipid soluble molecules from entering the CNS $[12,13]$. Peptides and proteins with molecular weights in excess of $600 \mathrm{Da}$ are known to cross the BBB in amounts sufficient to affect CNS function. Early examples include delta sleep-inducing peptide and enkephalin analogs. The largest substance found to date to cross the BBB by the mechanism of transmembrane diffusion is 
cytokine-induced neutrophil chemoattractant-1 (CINC1) at $7,800 \mathrm{Da}[14]$.

Lipophilic substances of low molecular weight tend to be substrates for P-glycoprotein [12]. Brain-to-blood efflux by P-glycoprotein can greatly limit the rate of uptake by the $\mathrm{BBB}$ and is a major obstacle in drug development. The pharmacogenomics of P-glycoprotein show that about $30 \%$ of the population overexpress it and so are less sensitive to the CNS effects of its ligands, while about $25 \%$ of the population underexpress it [15]. Such individual variation has been linked to sensitivity to drugs for the treatment of AIDS and epilepsy $[15,16]$.

\section{Saturable transport systems}

Some drugs or substances used for drug-like effects cross the BBB by use of saturable transport systems. L-DOPA and caffeine are examples as are vitamins such as B12 and B6 [17]. The uptake rate across the BBB for an endogenous ligand of a transporter is roughly about 10 times higher than would be expected if it crossed by transmembrane diffusion [18]. Additionally, many of the transporters for regulatory molecules, such as peptides and regulatory proteins, are taken up selectively by specific brain regions $[19,20]$. Thus, exploitation of transporters offer the drug development field not only high uptake rates for large, water soluble compounds but targeting to specific regions of the CNS.

Efflux transporters have the opposite effect to influx transporters in that they decrease the uptake rate of potential drugs [13]. P-glycoprotein has been discussed above, but the BBB possesses many other efflux transporters. As discussed below, peptide transport system-6 (PTS-6) retards the accumulation from blood by brain of the 27 amino acid form of pituitary adenylate cyclase activating polypeptide (PACAP27) [21].

The rate at which saturable systems transport their ligands across the BBB is often regulated. For flow-dependent substances such as glucose, transport rate is a function of cerebral blood flow [5]. For substances that are more slowly transported, a variety of agents have been found to alter transport. For example, leucine regulates the transport rate of peptide transport system-1 (PTS-1) [22] and epinephrine and triglycerides affect leptin, ghrelin, and insulin transport [23-25].

Under physiological conditions, the $\mathrm{BBB}$ transporters adapt to serve the needs of the CNS. Uncoupling between BBB functions and CNS needs is accompanied by disease states [26]. For example, decreased leptin transport is associated with peripheral leptin resistance in obesity [27] and decreased efflux of amyloid beta protein is associated with Alzheimer's disease [28].

\section{General strategies for drug transport}

A great deal of current effort towards drug development is directed towards in silico analysis and high-throughput screening. Such efforts limit drug discovery to substances crossing the BBB by transmembrane diffusion. They also limit discovery to the main parameters in the library used as the basis of computation. In silico methods are likely less efficient in the search for CNS drug candidates than in the search for those absorbed by the gastrointestinal tract because of a number of parameters that can modify or override transmembrane diffusion: cerebral blood flow, influx and efflux transporters, protein binding in the blood, clearance from blood, sequestration by BBB tissues, and enzymatic activity by peripheral tissues, blood, the CNS and at the BBB [5].

Many approaches to drug development have attempted to harness transporters. The usual approach is a version of the 'Trojan horse' strategy [29]. Here, a substance that does not cross the BBB is coupled to a substance that does. Such coupling can have the added benefit of improving peripheral pharmacokinetics. Unfortunately, the resulting hybrid compound is often not recognized by the original transporter or the transporter/hybrid compound is routed to lysosomes for destruction. Hybrids coupled to other substances may use other vesicular pathways across the BBB. Unfortunately, the cell biology of BBB vesicular systems is poorly understood and this impairs exploitation of promising leads.

Development of analogs of transported ligands has been slow. Many endogenous substances that could be the basis of CNS drugs, such as the feeding hormones and cytokines, are transported across the BBB [30]. However, the endogenous compounds have poor peripheral pharmacokinetics and this limits their usefulness [3]. Analogs would have to retain their affinity for both the BBB transporter and for the CNS receptor while becoming less favorable for peripheral enzymes and clearance mechanisms.

When disease states affect the $\mathrm{BBB}$ or the $\mathrm{BBB}$ is itself impaired, then it becomes a therapeutic target in its own right [26]. A classic example is multiple sclerosis in which the BBB becomes leaky and allows the entry of immune cells into the CNS. However, the passage of immune cells across the BBB is a highly regulated process [31] and the leakage is likely a byproduct of immune cell trafficking and not the other way round [32]. Obviously, the luminal surface of the capillary bed does not require passage across the BBB and, hence, drug strategies used to target peripheral tissues are applicable to this half of the BBB. Luminal receptors that induce brain endothelial cells to secrete into the CNS substances such as prostaglandins, cytokines, and nitric oxide are also readily targetable. This suggests that the BBB itself could be used as the source of CNS 'drugs'. 
'Bypassing' the BBB can also be an effective strategy, especially for selected cases or situations. For example, intrathecal administration for delivery of drug to the brain is ineffectual for small, lipid soluble drugs [33]. However, this route may be an option for large regulatory proteins with negligible brain-to-blood efflux [34]. Intranasal delivery of drugs, including peptides [35], shows a great deal of promise [36]. Nasal delivery of insulin, for example, has had positive effects in treating Alzheimer's disease $[37,38]$.

\section{Examples and special cases}

The various strategies used to develop drugs towards the CNS are meeting with varied levels of success. Those that consider the special features of the BBB rather than 'black boxing' it, attempt to understand the underlying mechanisms of promising leads, and consider the peripheral pharmacokinetics of the candidate drug should have advantages. However, there is a great deal that is unknown about the BBB that would be of great use to CNS drug development. For example, there are likely a great many BBB transporters yet to be discovered. Below, we consider two newly discovered transporters and their early applications to drug development.

Antisense molecules have been assumed to be incapable of crossing the BBB. The rapid clearance of any mRNA material in the circulation would certainly justify this assumption. However, enzymatically resistant analogs such as peptide nucleic acids and phosphorothioate oligonucleotides (PONs) can cross the BBB in sufficient amounts to affect CNS function [39,40]. The PONs are transported across the BBB by a saturable transport system. This transporter has been used to deliver an antisense molecule directed against amyloid precursor protein, which effectively reverses the cognitive deficit in an animal model of Alzheimer's disease. PONs have also been directed at the efflux transporter of PACAP27 [41]. The PONs reduce expression of the transporter, increase PACAP27 retention by brain after its peripheral administration, and improve outcomes in animal models of stroke and Alzheimer's disease. These results show that targeting efflux systems at the BBB with antisense molecules can improve drug delivery to the brain.

Mucopolysaccharidoses consist of a number of diseases in which missing enzymes lead to the accumulation of glycosaminoglycans in brain and peripheral tissues. Enzyme replacement clears the glycosaminoglycans from the peripheral tissues, but not from the CNS as the enzymes do not cross the BBB. However, it was recently discovered that the mannose- 6 phosphate receptor acts as a saturable transporter at the neonatal BBB $[42,43]$. As a result, enzyme given to the neonate is effective in clearance of glycosaminoglycans from the CNS [44-46]. Unfortu- nately, this transport function is lost with development. Recent work has shown that transporter function can be re-induced in the adult with epinephrine [47]. How epinephrine invokes this re-induction of activity is unclear, but it may be a useful strategy for delivery of enzyme to the CNS.

\section{Conclusion}

The BBB is a complex regulatory interface that possesses barrier, secretory, enzymatic, and transporter activities. Transmembrane diffusion, harnessing of transporters, adsorptive endocytosis, and extracellular pathways are some of the mechanisms being exploited for drug delivery. Unfortunately, our understanding of the BBB in many areas, especially those of saturable transport systems and vesicular pathways, is limited. Future successes in CNS drug discovery will likely result from an interplay of exploratory research and rational drug development.

\section{List of abbreviations used}

BBB: blood-brain barrier; CNS: central nervous system; CSF: cerebrospinal fluid; PACAP: pituitary adenylate cyclase activating polypeptide; PON: phosphorothioate oligonucleotide.

\section{Competing interests}

The author is a shareholder in EDUNN, a biotech company investigating the development of antisense molecules for the treatment of Alzheimer's and other CNS diseases.

\section{Acknowledgements}

This article has been published as part of BMC Neurology Volume 9 Supplement I, 2009: Proceedings of the 2009 Drug Discovery for Neurodegeneration Conference. The full contents of the supplement are available online at http://www.biomedcentral.com//47I-2377/9? issue=SI.

\section{References}

I. Neuwelt E, Abbott NJ, Abrey L, Banks WA, Blakley B, Davis T, Engelhardt B, Grammas P, Nedergaard M, Nutt J, Pardridge W, Rosenberg GA, Smith Q, Drewes LR: Strategies to advance translational research into brain barriers. Lancet Neurol 2008, 7:84-96.

2. Johanson CE, Duncan JA, Stopa EG, Baird A: Enhanced prospects for drug delivery and brain targeting by the choroid plexusCSF route. Pharm Res 2005, 22:101 I-1037.

3. Begley DJ: Delivery of therapeutic agents to the central nervous system: the problems and the possibilities. Pharmacol Ther 2007, 104:29-45.

4. Quan N, Banks WA: Brain-immune communication pathways. Brain Behav Immun 2007, 2 I:727-735.

5. Greig NH, Brossi A, Pei XF, Ingram DK, Soncrant TT: Designing drugs for optimal nervous system activity. In New Concepts of a Blood-brain Barrier Edited by: Greenwood J, Begley DJ, Segal MB. New York: Plenum Press; 1995:25I-264.

6. Reese TS, Karnovsky MJ: Fine structural localization of a bloodbrain barrier to exogenous peroxidase. J Cell Biol 1967, 34:207-2I7.

7. Banks WA: Are the extracellular pathways a conduit for the delivery of therapeutics to the brain? Curr Pharm Des 2004, 10:1365-1370.

8. Broadwell RD: Transcytosis of macromolecules through the blood-brain barrier: a cell biological perspective and critical appraisal. Acta Neuropathol 1989, 79: I 17-128. 
9. Oldendorf $\mathrm{WH}$ : Lipid solubility and drug penetration of the blood-brain barrier. Proc Soc Exp Biol Med 1974, 147:8I3-816.

10. Lipinski CA, Lombardo F, Dominy BW, Feeney PJ: Experimental and computational approaches to estimate solubility and permeability in drug discovery and developmental settings. Adv Drug Deliv Rev 1997, 23:3-25.

II. Levin VA: Relationship of octanol/water partition coefficient and molecular weight to rat brain capillary permeability. J Med Chem 1980, 23:682-684.

12. Begley DJ: ABC transporters and the blood-brain barrier. Curr Pharm Des 2004, 10:1295-1312.

13. Taylor EM: The impact of efflux transporters in the brain on the development of drugs for CNS disorders. Clin Pharmacokinet 2002, 41:81-92.

14. Pan W, Kastin A]: Changing the chemokine gradient: CINCI crosses the blood-brain barrier. I Neuroimmunol 200I, I I 5:64-70.

15. Fellay J, Marzolini C, Meaden ER, Back DJ, Buclin T, Chave JP, Decosterd LA, Furrer H, Opravil M, Pantaleo G, Retelska D, Ruiz L, Schinkel AH, Vernazza P, Eap CB, Telenti A, Swiss HIV Cohort Study: Response to antiretrovial treatment in HIV-I infected individuals with allelic variants of the multidrug resistance transporter I: a pharmacogenetic study. Lancet 2002, 359:30-36.

16. Löscher W, Potschka $\mathrm{H}$ : Role of multidrug transporters in pharmacoresistance to antiepileptic drugs. J Pharmacol Exp Ther 2002, 30:7-14

17. Davson $H$, Welch $K$, Segal MB: Some special aspects of the blood-brain barrier. In The Physiology and Pathophysiology of the Cerebrospinal Fluid Edinburgh: Churchill Livingstone; 1987:247-374.

18. Oldendorf WH: Brain uptake of radio-labelled amino acids, amines and hexoses after arterial injection. Am J Physiol I97I, 221:1629-1639.

19. Banks WA, Kastin AJ: Differential permeability of the bloodbrain barrier to two pancreatic peptides: insulin and amylin. Peptides 1998, 19:883-889.

20. Banks WA, Moinuddin A, Morley JE: Regional transport of TNF$\alpha$ across the blood-brain barrier in young ICR and young and aged SAMP8 mice. Neurobiol Aging 2001, 22:67I-676.

21. Banks WA, Kastin AJ, Komaki G, Arimura A: Passage of pituitary adenylate cyclase activating polypeptide ${ }_{1-27}$ and pituitary adenylate cyclase activating polypeptide $\left.\right|_{-38}$ across the blood-brain barrier. J Pharmacol Exp Ther 1993, 267:690-696.

22. Banks WA, Kastin A): Modulation of the carrier-mediated transport of the Tyr-MIF-I across the blood-brain barrier by essential amino acids. J Pharmacol Exp Ther 1986, 239:668-672

23. Banks WA, Coon AB, Robinson SM, Moinuddin A, Shultz JM, Nakaoke $\mathrm{R}$, Morley JE: Triglycerides induce leptin resistance at the blood-brain barrier. Diabetes 2004, 53:1253-1 260.

24. Banks WA, Burney BO, Robinson SM: Effects of triglycerides, obesity, and starvation on ghrelin transport across the blood-brain barrier. Peptides 2008, 29:206I-2065.

25. Urayama A, Banks WA: Starvation and triglycerides reverse the obesity-induced impairment of insulin transport at the blood-brain barrier. Endocrinology 2008, 149:3592-3597.

26. Banks WA: Editorial: The blood-brain barrier as a cause of disease. Curr Pharm Des 2008, 14:1553-1554.

27. Banks WA: The blood-brain barrier as a cause of obesity. Curr Pharm Des 2008, 14:1606-16|4.

28. Deane $R$, Sagare A, Zlokovic $B$ : The role of the cell surface LRP and soluble LRP in blood-brain barrier $A \beta$ clearance in Alzheimer's disease. Curr Pharm Des 2008, 14:1601-1605.

29. Penichet ML, Kang YS, Pardridge WM, Morrison SL, Shin SU: An antibody-avidin fusion protein specific for the transferrin receptor serves as a delivery vehicle for effective brain targeting: initial applications in anti-HIV antisense drug delivery to the brain. J Immunol 1999, 163:442 I-4426.

30. Pan W, Kastin AJ: Cytokine transport across the injured bloodspinal cord barrier. Curr Pharm Des 2008, 14:1620-1624.

31. Engelhardt B: The blood-central nervous system barriers actively control immune cell entry into the central nervous system. Curr Pharm Des 2008, 14:1555-1565.

32. Toborek M, Lee YW, Flora G, Pu H, András IE, Wylegala E, Hennig B, Nath A: Mechanisms of the blood-brain barrier disruption in HIV-I infection. Cell Mol Neurobiol 2005, 25:181-199.

33. McQuay HJ, Sullivan AF, Smallman K, Dickenson AH: Intrathecal opioids, potency and lipophilicity. Pain 1989, 36: I II-I I5.
34. McCarthy T], Banks WA, Farrell CL, Adamu S, Derdeyn CP, Snyder AZ, Laforest R, Litzinger DC, Martin D, LeBel CP, Welch MJ: Positron emission tomography shows that intrathecal leptin reaches the hypothalamus in baboons. J Pharmacol Exp Ther 2002, 307:878-883

35. During MJ, Cao L, Zuzga DS, Francis JS, Fitzsimons $\mathrm{HL}$, Jiao $X$, Bland RJ, Klugmann M, Banks WA, Drucker DJ, Haile CN: Glucagon-like peptide-I receptor is involved in learning and neuroprotection. Nat Med 2003, 9: I I73-I I 79.

36. Frey WH II: Bypassing the blood-brain barrier to deliver therapeutic agents to the brain and spinal cord. Drug Deliv Technol 2002, 2:46-49.

37. Reger MA, Watson GS, Green PS, Baker LD, Cholerton B, Fishel MA, Plymate SR, Cherrier MM, Schellenberg GD, Frey WH 2nd, Craft S: Intranasal insulin administration dose-dependently modulates verbal memory and plasma amyloid-beta in memoryimpaired adults. J Alzheimers Dis 2008, 13:323-331.

38. Benedict C, Hallschmid M, Hatke A, Schultes B, Fehm HL, Born J, Kern W: Intranasal insulin improves memory in humans. Psychoneuroendocrinology 2004, 29: | 326-1334.

39. Tyler BM, Jansen K, McCormick DJ, Douglas CL, Boules M, Stewart JA, Zhao L, Lacy B, Cusack B, Fauq A, Richelson E: Peptide nucleic acids targeted to the neurotensin receptor and administered i.p. cross the blood-brain barrier and specifically reduce gene expression. Proc Natl Acad Sci USA 1999, 96:7053-7058.

40. Banks WA, Farr SA, Butt W, Kumar VB, Franko MW, Morley JE: Delivery across the blood-brain barrier of antisense directed againt amyloid $\beta$ : reversal of learning and memory deficits in mice overexpressing amyloid precursor protein. J Pharmacol Exp Ther 200I, 297:III3-II2I.

41. Dogrukol-Ak D, Kumar VB, Ryerse IS, Farr SA, Verma S, Nonaka N, Nakamachi T, Ohtaki H, Niehoff ML, Edwards JC, Shioda S, Morley JE, Banks WA: Isolation of peptide transport system-6 from brain endothelial cells: therapeutic effects with antisense inhibition in Alzheimer's and stroke models. J Cereb Blood Flow Metab 2009, 29:4II-422.

42. Urayama A, Grubb JH, Sly WS, Banks WA: Developmentally regulated mannose 6-phosphate receptor-mediated transport of a lysosomal enzyme across the blood-brain barrier. Proc Natl Acad Sci USA 2004, I 01 : I 2658- 12663.

43. Urayama A, Grubb JH, Sly WS, Banks WA: Mannose 6-phosphate receptor mediated transport of sulfamidase across the blood-brain barrier in the newborn mouse. Mol Ther 2008 16:126I-1266.

44. Auclair D, Hopwood Jl, Brooks DA, Lemontt JF, Crawley AC Replacement therapy for mucopolysaccharidosis type VI: advantages of early onset of therapy. Mol Genet Metab 2003, 78:163-174.

45. Gliddon BL, Hopwood Jj: Enzyme-replacement therapy from birth delays the development of behavior and learning problems in mucopolysaccharidosis type IIIA mice. Pediatr Res 2004, 56:1-8.

46. Vogler C, Levy B, Galvin NJ, Thorpe C, Sands MS, Barker JE, Baty J, Birkenmeier EH, Sly WS: Enzyme replacement in murine mucopolysaccharidosis type VII: neuronal and glial response to beta-glucuronidase requires early initiation of enzyme replacement therapy. Pediatr Res 1999, 45:838-844.

47. Urayama A, Grubb JH, Banks WA, Sly WS: Epinephrine enhances lysosomal enzyme delivery across the blood-brain barrier by up-regulation of the mannos 6-phosphate receptor. Proc Natl Acad Sci USA 2007, 3 I: 12873-12878. 